\title{
TITLE: THE GLOBAL FILIPINO NURSE: AN INTEGRATIVE REVIEW OF FILIPINOS NURSES' WORK EXPERIENCES
}

\author{
Jed MONTAYRE, RN, PhD \\ Lecturer-Nursing \\ School of Clinical Sciences \\ Auckland University of Technology \\ 90 Akoranga Drive, Northcote, Auckland, New Zealand \\ +64099219999 \\ jed.montayre@aut.ac.nz \\ Jasmine MONTAYRE, RN, CertT \\ Clinical Educator- Nursing \\ School of Clinical Sciences \\ Auckland University of Technology \\ 90 Akoranga Drive, Northcote, Auckland, New Zealand \\ +64099219999 \\ jasmine.montayre@aut.ac.nz
}

Eleanor HOLROYD PhD

Professor of Nursing

Professorial Fellow School of Global and Population Health, University of Melbourne,

Visiting Professor National University of Singapore, Adjunct Professor CUHK Public

Health,

School of Clinical Sciences

AUT University

90 Akoranga Drive, Northcote, Auckland, New Zealand

+64099219999

eleanor.holroyd@aut.ac.nz

This is the author manuscript accepted for publication and has undergone full peer review but has not been through the copyediting, typesetting, pagination and proofreading process, which may lead to differences between this version and the Version of Record. Please cite this article as doi: $10.1111 /$ jonm.12552

This article is protected by copyright. All rights reserved 


\section{Corresponding Author:}

Jed MONTAYRE, RN, PhD

Lecturer-Nursing

School of Clinical Sciences

Auckland University of Technology

90 Akoranga Drive, Northcote, Auckland, New Zealand

+64099219999 Ext 6056

Mobile: +64275131108

jed.montayre@aut.ac.nz

\section{Word Count: 5,153}

Funding: No funding was received

The authors declare no conflict of interest.






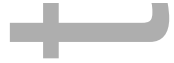 \\ Article type : Review Article \\ The Global Filipino Nurse: An Integrative Review of Filipinos Nurses' Work Experiences}

\section{Abstract}

Aim To understand the work-related experiences of Philippine-trained nurses working globally.

Background The Philippines is one major source country of foreign-trained nurses located globally. However there is paucity of research on professional factors and career related issues affecting foreign-trained nurses' work experiences.

Methods Integrative review through a comprehensive search of literature was undertaken from November 2015 and was repeated in August 2016. Seven articles satisfied the selection criteria.

Results Filipino nurses experienced differences in the practice of nursing in terms of work process, roles, and autonomy. Moreover, they encountered challenges such as work-related discrimination and technical difficulties within the organisation.

Conclusion Clear understanding of Filipino nurses' work experiences and the challenges they have encountered suggests identification of important constructs influencing effective translation of nursing practice across cultures and health systems, which then form the basis for support strategies.

Implication for Nursing Management It is critical to recognise foreign-trained nurses' experience of work-related differences and challenges as these foster favourable conditions for the management team to plan and continually evaluate policies around recruitment, retention and support offered to these nurses. Furthermore, findings suggest 
internationalisation of nursing framework and standards integrating a transcultural paradigm among staff members within a work organisation.

Keywords: Filipino nurses, global nurse migration, work experiences, integrative review

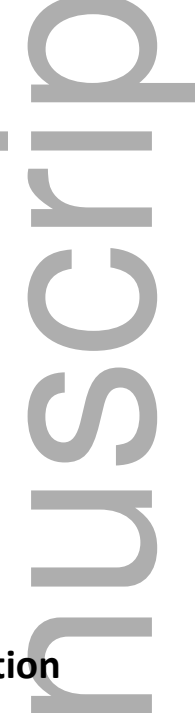

The migration of healthcare professionals is a continuing global phenomenon. Nurses, in particular rank the highest among healthcare professionals dominating the migrant workforce in most developed countries (Brush 2008). Furthermore, current motivators for nurse migration are no longer limited to seeking better economic opportunities but also in seeking improved professional and career pathways (Dywili et al. 2013, Aiken et al. 2004). Previous research on nurse migration were largely focused on the motivators and on the push-pull factors (Kline 2003). However there is paucity of research on professional factors and career related issues affecting foreign-trained nurses' work experiences.

The Philippines is one major source country of foreign-trained nurses located globally. Since the 1970s, nurses have left the Philippines to work in developed countries like the United States, Canada, United Kingdom and in the Middle East (Brush \& Berger 2002, Brush \& Sochalski 2007). In 2000, it was estimated that a quarter of a million Filipino nurses work overseas (Ball 2004). To date the majority of research on nurse workforce migration has focused on the life experiences surrounding settlement challenges (Brown \& James 2000), experiences and acculturation in destination societies (Ea et al. 2008). There has been little research focusing specifically on Philippine-trained nurses' work experience and professional acculturation in the host countries despite being one of the largest nurse migrant group. Furthermore, the increasing diversity within the nursing workforce suggests 
a strong focus on nurses from different backgrounds contributing towards positive health outcomes in nurse importing countries (Villarruel et al. 2015). This integrative review of literature presents a contemporary critique of the Filipino nurses' work experience globally using articles published from the year 2000. This review adds to the literature on migrant nursing workforce and informs the international nursing leadership and management in exploring recruitment and retention strategies specific to Filipino nurses, which contributes to building a stable nursing workforce and sustainable population health outcomes.

\section{Research Aim}

This integrative review aimed to provide a contemporary understanding of the work-related experiences of Philippine-trained nurses working globally. This review was guided by the following objectives:

1. Describe the nursing work experience of the global Filipino nurse.

2. Identify challenges accompanying nursing work experience of the global Filipino nurses.

\section{Method}

Integrative reviews examine primary research informed by mixed and diverse methodologies to synthesise a novel understanding of a particular phenomenon or variable (Whittemore \& Knalf 2005). This methodology follows a robust step-by-step process namely problem identification, literature search, data evaluation, data analysis (reduction, display, comparison, conclusion drawing and verification) and presentation of synthesised ideas with an emphasis towards implications to practice (Whittemore \& Knalf 2005). A quality appraisal was conducted using the Mixed Method Appraisal Tool (MMAT) by Pluye et al. (2011) to determine methodological quality of articles selected to be part of this review.

\section{Search Strategy}

A comprehensive search of literature were undertaken through electronic databases (CINAHL, Medline, PubMed, Scopus and Google Scholar) using the search terms 'nursing work, work experience, Filipino nurse' AND 'registered nurse, migrant nurses, overseastrained staff' AND 'Filipino' and synonymous terms such as 'foreign-trained nurses, internationally qualified nurses, nurse migration' AND/OR 'Philippine-trained nurse'. The keywords 'overseas nursing work' were also searched as an equivalent and commonly 
substituted terms for 'work experience' in the literature. Limiters were applied with the database searching which narrowed the search to peer-reviewed articles from an academic journal, written in English, available in full text and published from January 2000 to January 2016. A specific publication period was strictly followed in excluding articles as it needs to align with the review objectives of the exploring contemporary work experience of Filipino nurses. Search aides through Boolean operators and truncated terms (e.g. nurs* and nurs* migration) were also applied for database searching. With the current review, each reviewer further conducted a manual search for potential studies for inclusion from the retrieved articles' reference lists. The inclusion and exclusion criteria were outlined to provide a wellgrounded selection process. This is summarised in Table 1.

(INSERT TABLE 1 HERE)

\section{PRISMA Screening}

Initial online database search was conducted in November 2015 and was repeated in August 2016. First and second reviewers facilitated the use of the PRISMA framework (Moher et al. 2009) in the selection process. The search had 108 hits using the combination of search terms with limiters applied as mentioned previously. Duplicates of articles were removed from each database, which left 44 records. Ancestral searching yielded additional 4 potential articles. When inclusion and exclusion criteria were applied, 17 full text articles remained. A staged screening was conducted starting from titles and abstracts, which removed 6 articles and then excluded further 4 articles after a detailed full text evaluation due to other reasons stated in exclusion criteria. Ancestral searching contributed one study for inclusion. Finally, seven studies were included in the review as outlined in the PRISMA framework (summarised in Figure 1). These articles met the outlined inclusion and exclusion criteria for selection.

\section{(INSERT FIGURE 1 HERE)}

\section{Quality Appraisal}

The appraisal checklist, MMAT (Pluye et al. 2011) was modified with permission by utilising only the applicable aspects of the tool fitted to the methodologies utilised in the studies appraised, which were composed of five qualitative articles and two using a mixed-method 
approach (Table 2). A section appraising ethics within studies was added in the tool. The tool provided a consistent single-format quality evaluation of studies from diverse methodological approaches selected for this current review.

All three reviewers independently conducted the quality appraisal and the careful review of all seven studies. Quality or data evaluations adds rigour to the review and is a critical step in determining the strength and influence selected studies have on the overall analysis and synthesis of results, which is predominantly based on methodological quality. While the appraisal undertaken was made to ascertain quality, it did not result to reviewers' deciding to exclude certain relevant articles due to lower quality scores as compared to others. Instead, the findings of articles appraised to be weaker were treated with caution and had lesser reference in the weighing of relevant finding within the conclusion drawing process (Whittemore and Knalf 2005). Based on quality scores and critical review of the quality, a consensus was made amongst reviewers that all selected articles were methodologically sound and have satisfied the MMAT criteria. Data analysis followed the quality appraisal through presentation of review findings and formation thematic groups from the data abstracted and synthesised.

\section{Data Abstraction and Synthesis}

Whittemore and Knalf (2005) framework for data analysis of integrative reviews was adhered in this current review. All articles were read fully with care and data synthesis was derived from following the processes of data reduction, data display, data comparison and conclusion drawing with verification. Stepwise, data was reduced by establishing an overall taxonomy in extracting data from diverse methodologies through logical grouping of data according to type of evidence, research design, settings and sample characteristics and then coded inductively, which were then outlined to form a conceptual map (data display). The interrelated conceptual data were then compared and contrasted in an iterative process (data comparison) and then regrouping to similar concepts or themes. A pattern is then identified for similarities and differences needed in drawing the conclusion (Whittemore \& Knalf 2005).

\section{RESULTS}

\section{Data Characteristics}

This article is protected by copyright. All rights reserved 
Seven research articles were included in this review. Articles were primary research published from 2001 to 2014 (see Table 2). Five studies were qualitative and two utilised mixed methods. There was no primary quantitative research found in the literature focussing on nursing experience solely for Filipino nurses. Diverse qualitative approaches were identified for five studies with different methods utilised: qualitative approach using focus group discussions (Daniel et al. 2001, Vestal \& Kautz 2009), phenomenology with focus group interviews (McGonaglen et al. 2004), oral history using individual interviews (Ronquillo 2012) and cross-sectional research using in-depth interviews (Connor \& Miller 2014).

The two mixed method studies were conducted through questionnaires and semi-structured interviews (Withers \& Snowball 2003) and using a standardised instrument with individual interviews (Hayne et al. 2009) respectively. The sample size for all seven articles ranges from eight to twenty-four nurses. Majority of study participants were females. The topic on nursing work experience of Filipino nurses was explored within countries identified as large global importers of foreign-trained nurses, where published articles included in this review represented studies from US $(n=3)$, UK $(n=3)$ and Canada $(n=1)$. Interestingly, there were no published articles from the Middle East, African, European and Australasian region eligible for this review, which perhaps might have been limited due to the inclusion and exclusion criteria being applied. Themes were synthesised from the review, which has provided clear insights on the nursing experiences of Philippine-trained nurses. In this current review, two emerging themes were identified (1) differences in the practice of nursing and (2) challenges in the practice of nursing encountered by Filipino nurses. Subthemes were discussed under each theme identified.

\section{(INSERT TABLE 2 HERE)}

\section{Differences in the Practice of Nursing}

From the current review, Philippine-trained nurses have observed and encountered differences in the practice of nursing between the Philippines and their host countries. This review revealed that Filipino nurses find nursing work process, roles, and autonomy to be different from their home country. These findings on the aspects of differences of nursing 
practice were consistent in the seven articles reviewed. These differences were exemplified in the following critical discussion of the subthemes.

(INSERT TABLE 3 HERE)

\section{a. Work Process}

Work processes were observed to be different in terms of organisation of work and the routine nurses do in the host countries (Daniel et al. 2001, Vestal \& Kautz 2009, Withers \& Snowball 2003). One notable issue is the differing procedures and process of administering medications, where nurses in host countries are expected to give medications only to their respective patients unlike the common Philippine system where nurses function as the shift's assigned 'medication nurse' expected to administer medication to all patients in the unit (Daniel et al. 2001). Another aspect was the practice of handing over unfinished nursing tasks to the next shift (Daniel et al. 2001, Withers \& Snowball 2003), which Filipino nurses felt uncomfortable with as they had set expectations of finishing all tasks within their shift even if it has resulted in missing breaks and staying longer after their shift. Vestal and Kautz (2009) found out that Filipino nurses are finding the use of technology different as much more sophisticated when compared to that of the Philippines. Although earlier research included in this review, Withers and Snowball (2003) captured Filipino nurses' disappointment on outdated technology being used in older hospitals in the UK, which was opposite to their expectations. Additionally, other work process factors that are new to Filipino nurses are the short changes in the duty roster for example, a nurse works for two consecutive afternoon shifts then works for a morning shift on the third day of work (Vestal \& Kautz, 2009).

Furthermore, the system of carrying out doctors' orders in host countries through verbal communication for some procedures is unlikely in the Philippines, where nurses follow written doctors' orders at all times (Daniel et al. 2001). While the work process is viewed to be extensively different, the principles of nursing remained the same. One study revealed from Filipino nurses suggesting that what is all required for them to practice with ease is to become familiar with the routine on how major aspects of nursing work are specifically undertaken in the host country (Daniel et al. 2001).

\section{b. Roles}


This review revealed that Filipino nurses observed differences in terms of what nurses assume as responsibilities within their work roles (Daniel et al. 2001, Withers \& Snowball 2003, Hayne et al. 2009) and the perceived role of families (Daniel et al. 2001, McGonagle et al. 2004, Vestal \& Kautz 2009), which plays an important part to how nursing care is provided. In the UK, Daniel et al. (2001) mentioned the differences in the varying specialised roles of nurses such as stoma nurses, infection control nurses and others. While in the Philippines all of these roles considered specialised tasks in the UK were expected within the practice of general nursing. Also family members provide assistance and personal care (e.g. hygiene) to their hospitalised family member in the Philippines, tasks that nurses do in the host countries. The review also found out that this role difference was clear to Filipino nurses with only very few nurses finding their roles as not so overt (Hayne et al. 2009). Additionally, from a US study, the role of nurses in the Philippines were perceived by some Filipino nurses to be very dependent to the practice of medicine (Withers \& Snowball 2003).

\section{c. Autonomy}

Autonomy and particular sense of agency were seen to be exercised by Filipino nurses from the Philippines compared to their counterparts from their host countries. Autonomy synthesised from this review encompassed both decision-making (Daniel et al. 2001, McGonagle et al. 2004, Ronquillo 2012) and power dynamics in nurse-doctor relationships (Withers \& Snowball 2003, Ronquillo 2012).

Differences in an autonomous nursing decision-making were presented with opposing views in this review. Daniel et al. (2001) found that there was less autonomy among nurses in the host country than for the foreign-trained nurses. This finding is further supported by McGonagle (2004) in comparing how Filipino nurses operationally define autonomous practice in the Philippines within the context of providing physical care to clients and in facilitating physician activities. While Filipino nurses in Canada, recognised the increased responsibility of nurses as decision-makers and had a more autonomous nursing experience (Ronquillo 2012). However, Filipino nurses who have worked from other developed countries draws comparisons and conclusions on one being more autonomous than others (Ronquillo 2012). 
The working relationship between nurses and physician in the host countries were viewed to be different from that practised in the Philippines. There is less hierarchal status between nurses and doctors, which was highlighted within nurses' ability to decide and contribute to the decision-making process regarding the care and interventions to be provided to patients (Ronquillo 2012). This difference was also emphasised in a UK study of Withers and Snowball (2003) quoting "nurses in the Philippines are very subservient to doctors and other senior nurses (p. 122).

\section{Challenges encountered}

Another major theme revealed in this review is the challenges experienced by Filipino nurses with their work. These challenges were considered as difficulties encountered and at the same recognising the differences which then becomes challenging to work as a nurse. There were two major subthemes for the challenges identified; work-related discrimination and work-related difficulties. For each subtheme more specific examples were exemplified from specific data extracted from this review.

\section{a. Work Related Discrimination}

This challenge was manifested in two ways as observed and experience by Filipino nurses. These are proving oneself over and over again (Daniel et al. 2001, Vestal \& Kautz 2009, Ronquillo 2012) and the feeling of being an outsider (Daniel et al. 2001, Withers \& Snowball 2003, Connor \& Miller 2014) were presented to be a form of work-related discrimination.

Showing professional competency and the ensuing trust by colleagues and patients were part of Filipino nurses work experience, particularly during the starting period of employment (Daniel et al. 2001). Stereotyping from staff and patients meant these Filipino nurses felt that they had to prove themselves continually. Thus, despite being trained and educated in a foreign country, Filipino nurses felt they were more than capable of conducting nursing within competency standards of their host countries (Vestal \& Kautz 2009, Ronquillo 2012). This phenomenon resulted in a perception that they (Philippinetrained nurses) were constantly being watched and observed by other staff (Daniel et al. 2001). Furthermore, Filipino nurses felt that their local colleagues do not respect their previous clinical experience and therefore placed in mentoring relationships (Withers \& 
Snowball 2003). Filipino nurses viewed mentorship by local nurses to be simultaneously advantageous and as well as undermining their skills (McGonagle et al. 2004).

Aside from having to prove oneself, another experience under work-related discrimination was the issue of coming from a different culture or of being an "outsider" (Ronquillo 2012). Negative discrimination were experienced by Filipino nurses especially when they use their own language when talking to other Filipino colleagues (Withers \& Snowball 2003). Nonacceptance also was is very common and the experience of being new or being not included triggered the feeling of uneasiness in the workplace among Filipino nurses (Daniel et al. 2001). Being an outsider as revealed in this review also meant belonging to different cultural group that do not identify the beliefs and culture of colleagues and patients in the host country (Connor \& Miller 2014).

\section{b. Work-Related Difficulties}

The other challenges experienced by Filipino nurses referred to the work-related difficulties in terms of communication (Daniel et al. 2001, Withers \& Snowball 2003, Connor \& Miller 2014) and issues with the use of country-specific technical terms in nursing and medicine (Daniel et al. 2001, Withers \& Snowball 2003, McGonagle et al. 2004), which varied from the Philippines. The communication concerns mainly focused on the use and understanding of English language between colleagues and patients. While the inadequate knowledge about accepted terms and commonly used technical nursing jargons from the host country posed these work-related difficulties.

The difficulties encountered regarding communication specifically identified the differences of accents and use of English language among staff and patients in the host countries (Daniel et al. 2001). Filipino nurses are accustomed to the American English system of writing and spoken expression that varies when working in the UK and other host countries. Although given that scenario, Filipino nurses working in the US still encounter issues with communication with regards to not being understood by patients, which has an impact on how they deliver their nursing job (Miller \& Connor 2014). On the other hand, Filipino nurses were not able to use their own language when talking to other Filipino nurses at work as this act receives negative discrimination among staff members (Withers \& Snowball 2003). Furthermore, this difficulty was not identified with written and spoken English 
language, instead focused on being accustomed to accents and use of common expression and terms within the language of the host country.

This difficulty posing a challenge for Filipino nurses was seen to be associated with the use of idioms and colloquial language in the host country which resulted in confusion (Daniel et al. 2001, Withers \& Snowball 2003). Also acceptable medical abbreviations poses misunderstandings for newly recruited Filipino nurses (Withers \& Snowball 2003) more so than new drug names did (Hayne et al. 2009). The use of jargon specific to the host country (Daniel et al. 2001) and issues around use of terms with documentation were specifically mentioned in one study from Ireland (McGonagle et al. 2004), which considerably contributed to this identified difficulty.

\section{Discussion}

The recognition of the differing frameworks and models of how nursing practice is delivered in host countries from the perspectives of Asian nurses has been well acknowledged in the nursing literature ( $\mathrm{Xu}$ 2007). However, the findings from this current integrative review highlighted specific dissimilarities such as work systems, roles and autonomy and as well as the challenges within the practice of nursing as experienced by Filipino nurses in the host countries.

A review of Filipino nurses' experience within nursing work systems, roles and autonomy in their host countries provides an informed thinking towards new foreign trained nurses' transition journey of practicing within a new healthcare system and culture. Healthcare systems in the Philippines face limited budgets relying on disease based interventions and not necessarily to the same standard and competency with those of developed countries (World Health Organisation 2011). Because of this Filipino nurses experience profoundly different nursing work system and roles in host countries to the practice they are accustomed to. Filipino nurses' comparison of autonomy in nursing practice was grounded in their country of origin practise of subservient roles to doctors within a medicalised healthcare framework. Whereas in most host countries, nurses' have autonomous roles, increased decision making power and actively contributing to care.

These differences enable clear identification of the professional nursing workforce sectors that need a strong focus during an orientation program or an adaptation course for Filipino 
nurses and by other foreign trained nurses. As migrant nurses increasingly occupy the nursing job market globally, it is imperative that a sound professional acculturation programme should be outlined towards safety, communication, documentation and effective translation of nursing practice.

The major challenges Filipino nurses encountered were work-related discrimination and difficulties. Filipino nurses had repeatedly prove their competency to both colleagues and to their patients. Similar finding has been contended in other migrant nurse groups and their relationship with local staff nurses (Alexis \& Vydelingum 2004). Moreover, one study noted that actions aimed to erode competence and attacks through work roles or tasks are identifiable forms of workplace bullying in nursing (Hutchinson et al. 2010). Many of these studies in this current review revealed that Filipino nurses felt excluded, which was similar to being treated indifferently as mentioned by Winkelmann-Gleed and Seeley (2005) study on migrant nurses' experience in the UK. Cultural and professional stereotyping was manifested within work environment with Filipino nurses' previous nursing experience being disregarded by some colleagues.

Work-related difficulties experienced by Filipino nurses highlighted communication, use of colloquial terms and dialects, which is not a new occurrence for migrant nurses (Lin 2009, Xu 2007). However, it is evident that specific difficulties were experienced by these Filipino nurses in using country-specific nursing abbreviations and terminologies and in understanding unfamiliar English accent or jargons. Communication complexities due to difficulty in recognising accent and together with the use of colloquial English language is reported to be experienced more frequently by foreign-born nurses, including Filipinos (Wagner et al. 2015).

The challenges experienced by Filipino nurses suggesting careful consideration of potential difficulties Philippine-trained nurses may encounter during their critical initial stages of employment. This calls for added efforts on warm welcome and acceptance of new Filipino nurses with consideration of the competence and knowledge they can contribute to the nursing team. Case in point, is their cultural accommodation for other Filipino patients, which contributes to overall healthcare outcomes within increasingly culturally diverse communities. Identifying the challenges faced in adjusting to new and unfamiliar terminologies has implications to safety of practice, clinical standards as well as avoiding 
misinterpretations of technical jargons and other medical abbreviations utilised in host countries (Kawi \& Xu 2009).

This current review revealed a contemporary understanding which calls for nurse leaders and health organizations in major nurse-importing countries to develop the managerial lens that recognises the work experiences of Filipino nurses globally. The acknowledgment of differences and challenges of nursing practice experience by Filipino nurses goes beyond skills and competencies required for nurses in the host countries, but is best understood by incorporating the transcultural implications that occur during these transition periods.

\section{Limitations}

The articles included in this review poses few limitations in terms of quality and representation of methodologies. Findings of articles with weaker quality were carefully extracted to maintain rigour of the review and quality of synthesised findings. Additionally, due to very limited availability of articles published on work experiences of Filipino nurses, there was no representation of studies employing primary quantitative methodology. However, Filipino nurses' experiences were reasonably explored using robust qualitative and mixed-method approaches in the articles included in the current review. Furthermore, the lack of advanced and generalised understanding of the experiences of Filipino nurses warrants research starting out to be explorative in nature. While it was also considered that despite the comprehensive search strategy applied to this review, some articles may have been missed due to unavailability of full-text access and other grounds within inclusion/exclusion criteria.

\section{Conclusion}

Filipino nurses pointed out the differences in the practice of nursing and the challenges they encounter working in a foreign country. The differences outlined important constructs influencing the manner how nursing practice can be translated from one setting to another. The identified challenges and difficulties provide the basis for targeting increased support for Filipino nurses. Moreover, having a clear understanding of Filipino nurses' nursing experiences and the challenges they have encountered suggests a review of internationalisation of policies and mandate governing nursing practice standards from both source and host countries. While the fundamental principles of nursing practice could be 
considered generalizable, given these identified differences across cultures and health care systems make nursing work relatively transferrable. This review calls for a strengthened and negotiated partnership in the practice of transcultural nursing among Filipino nurses and other migrant nurses.

\section{Implication for Nursing Management}

The global recruitment for internationally qualified nurses, particularly Filipino nurses will continue to increase in the next few decades. The findings of this review will inform nurse managers and human resource personnel in understanding the perspectives of Filipino nurses based on their work experience from the Philippines and in transitioning as nurses in the host country. Recognising differences and challenges fosters favourable conditions for the management team to plan and continually evaluate policies around recruitment, retention and support offered to Filipino nurses and other foreign-trained nurses. Additionally, nurse managers could develop research-informed and culturally targeted preceptorship programmes to assists new foreign-trained nurses and foster a healthy preceptor-orientee relationships. In a broader scope, findings could open a conversation on internationalisation of nursing framework and standards integrating a transcultural paradigm among staff members within a work organisation.

\section{Reference List:}

Aiken L.H., Buchan J., Sochalski J., Nichols B. \& Powell M. (2004) Trends in international nurse migration. Health Affairs 23 (3), 69-77.

Alexis, O. and Vydelingum, V. (2004) The lived experience of overseas black and minority ethnic nurses in the NHS in the south of England. Diversity in Health \& Social Care 1(1). 
Ball, Rochelle E. (2004). Divergent development, racialised rights: Globalised labour markets and the trade of nurses--The case of the Philippines. Women's Studies International Forum, 27, 119-133. doi:10.1016/j.wsif.2004.06.003

Brown, D. E., \& James, G. D. (2000) Physiological stress responses in Filipino-American immigrant nurses: the effects of residence time, life-style, and job strain. Psychosomatic Medicine 62(3), 394-400.

Brush B.L. \& Sochalski J. (2007) International nurse migration: lessons from the Philippines. Policy Politics and Nursing Practice 8 (1), 37-46.

Brush B.L. (2008) Global nurse migration today. Journal of Nursing Scholarship 40 (1), 20-25.

Brush, B.L. and Berger, A.M. (2002) Sending for nurses: Foreign nurse migration, 19652002. Nursing and Health Policy Review 1(2), pp.103-116.

Connor, Jorgia Briones \& Miller, Arlene Michaels. (2014) Occupational stress and adaptation of immigrant nurses from the Philippines. Journal of Research in Nursing 19, 504-515.

Daniel, P., Chamberlain, A. and Gordon, F. (2001) Expectations and experiences of newly recruited Filipino nurses. British Journal of Nursing 10(4), pp.254-265.

Dywili, S., Bonner, A., \& O’brien, L. (2013) Why do nurses migrate?-a review of recent literature. Journal of Nursing Management 21(3), 511-520.

Ea, E.E., Griffin, M.Q., L'eplattenier, N. and Fitzpatrick, J.J. (2008) Job satisfaction and acculturation among Filipino registered nurses. Journal of Nursing Scholarship 40(1), pp.46-51. 
Hayne, A.N., Gerhardt, C. and Davis, J. (2009) Filipino nurses in the United States:

Recruitment, retention, occupational stress, and job satisfaction. Journal of Transcultural Nursing 20(3) pp. 313-322.

Hutchinson, M., Vickers, M.H., Wilkes, L. and Jackson, D. (2010) A typology of bullying behaviours: the experiences of Australian nurses. Journal of Clinical Nursing 19(15-16), pp.2319-2328.

Kawi, J. and Xu, Y. (2009) Facilitators and barriers to adjustment of international nurses: an integrative review. International nursing review, 56(2), pp.174-183.

Kline D.S. (2003) Push and pull factors in international nurse migration. Journal of Nursing Scholarship 35 (2), 107-111.

Lin, L.C. (2009) A synthesis of the literature on Asian nurses' work experiences in the United States. Research and Theory for Nursing Practice 23(3), pp.230-245.

Mc Gonagle, C., Halloran, S.O. and O'Reilly, O. (2004) The expectations and experiences of Filipino nurses working in an intellectual disability service in the Republic of Ireland. Journal of Learning Disabilities 8(4), pp.371-381.

Moher, D., Liberati, A., Tetzlaff, J., Altman, D. G., \& The PRISMA Group (2009) Preferred reporting items for systematic reviews and meta-analyses: The PRISMA statement. PLOS Medicine 6(6), e1000097. http://dx.doi.org/10.1371/journal.pmed1000097.

Pluye, P., Robert, E., Cargo, M., Bartlett, G., O'Cathain, A., Griffiths, F., Boardman, F., Gagnon, M.P., \& Rousseau, M.C. (2011). Proposal: A mixed methods appraisal tool for systematic mixed studies reviews.

Available at: http://mixedmethodsappraisaltoolpublic.pbworks.com. Accessed 12 January 2015. 
Ronquillo, C., Boschma, G., Wong, S.T. and Quiney, L. (2011) Beyond greener pastures: exploring contexts surrounding Filipino nurse migration in Canada through oral history. Nursing inquiry 18(3), pp.262-275.

Vestal, V. and Kautz, D.D. (2009) Responding to similarities and differences between Filipino and American nurses. Journal of Nursing Administration 39(1), pp.8-10.

Villarruel, A., Washington, D., Lecher, W.T. and Carver, N.A. (2015) A more diverse nursing workforce. American Journal of Nursing, 115(5), pp.57-62.

Wagner, L.M., Brush, B.L., Castle, N.G., Eaton, M. and Capezuti, E. (2015) Examining differences in nurses' language, accent, and comprehensibility in nursing home settings based on birth origin and country of education. Geriatric Nursing 36(1), pp.47-51.

Whittemore, R., \& Knafl, K. (2005) The integrative review: update methodology. Journal of Advanced Nursing 52(5), 546-553.

Winkelmann-Gleed, A. and Seeley, J. (2005) Strangers in a British world? Integration of international nurses. British Journal of Nursing 14(18), pp.954-961.

Withers, J. and Snowball, J. (2003) Adapting to a new culture: a study of the expectations and experiences of Filipino nurses in the Oxford Radcliffe Hospitals NHS Trust. NT Research 8(4), pp.278-290.

World Health Organization (2011) The Philippines health system review. Manila: WHO Regional Office for the Western Pacific. Available at: http://iris.wpro.who.int/handle/10665.1/5536

$\mathrm{Xu}, \mathrm{Y}$. (2007) Strangers in strange lands: a metasynthesis of lived experiences of immigrant Asian nurses working in Western countries. Advances in Nursing Science 30(3), pp.246-26 


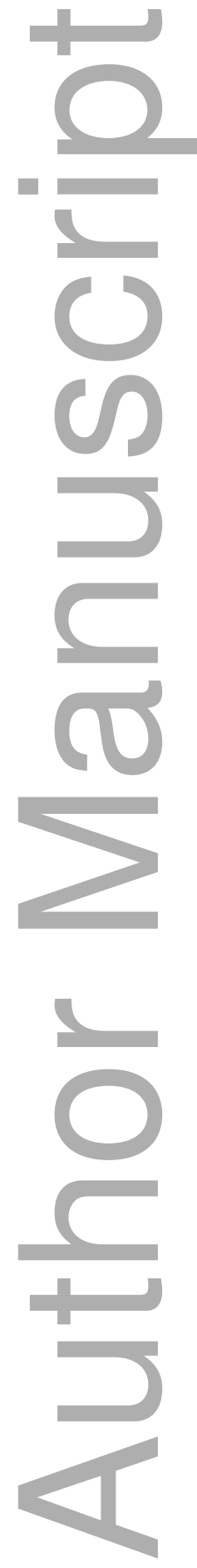

This article is protected by copyright. All rights reserved 


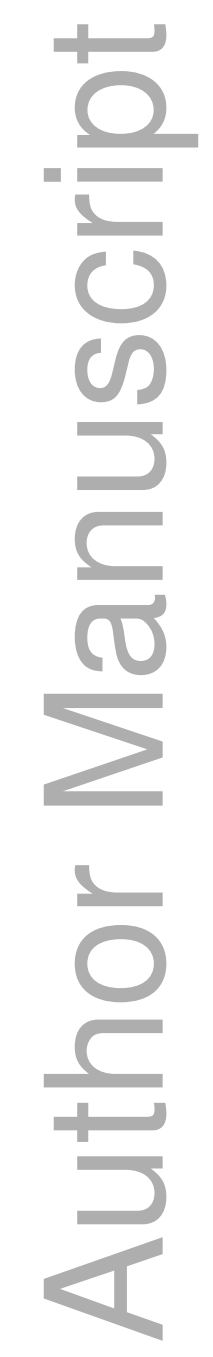

This article is protected by copyright. All rights reserved 


\begin{tabular}{|c|c|c|c|c|c|c|}
\hline $\begin{array}{l}\text { Study } \\
\text { no. }\end{array}$ & Author, Year, Country & Research Purpose & Methodology, Methods & Participants and Sample size & & $\begin{array}{l}\text { Major Findings } \\
\text { Specific to Nursing work experience }\end{array}$ \\
\hline 1 & $\begin{array}{l}\text { Daniel, Chamberlain \& } \\
\text { Gordon (2001), United } \\
\text { Kingdom (UK) }\end{array}$ & $\begin{array}{l}\text { Identify initial expectations and } \\
\text { experiences of newly recruited } \\
\text { Filipino nurses }\end{array}$ & $\begin{array}{l}\text { Qualitative approach using focus } \\
\text { group interviews }\end{array}$ & $\begin{array}{l}\text { 24 Filipino nurses (1 male, } 23 \text { females) } \\
\text { a. } 15 \text { first group ( } 1 \text { male, } 14 \\
\text { females), have spent } 3 \text { months in } \\
\text { the UK at time of study } \\
\text { b. } 9 \text { second group (females) in } \\
\text { hospital } 2 \text { week-orientation } \\
\text { program }\end{array}$ & 1) & $\begin{array}{l}\text { Filipino nurses are surprised at the different } \\
\text { specialisation roles of nurses in the UK (stoma } \\
\text { care nurse, etc.) while in the Philippines a } \\
\text { general floor nurse are expected to do all these } \\
\text { special and demanding tasks. Differences in } \\
\text { family involvement to patients' care (family } \\
\text { providing basic care) but not in UK leading to } \\
\text { nursing workload considered as 'heavy'. } \\
\text { Organisation of nursing work differences noted } \\
\text { (flow of duty, shift patterns, the meaning of } \\
\text { endorsement "handing over of unfinished } \\
\text { nursing tasks to the next shift", differing } \\
\text { procedures of giving medication, lesser } \\
\text { autonomy for nurses, putting patient notes at } \\
\text { the end of the bed, differences on the value } \\
\text { given by families/relatives towards older people } \\
\text { and the care provided to them. } \\
\text { Issues with communication with staff and } \\
\text { patients (accents and use of English language), } \\
\text { being bilingual and speaking with other Filipinos } \\
\text { using the native tongue can be a problematic. } \\
\text { Difficulty of using UK-based jargons and } \\
\text { terminologies as Filipino nurses are greatly } \\
\text { influenced by American system of education. } \\
\text { Nurses felt the practice of nursing is the same, } \\
\text { what is required for Filipino nurses is to get used } \\
\text { with the routine. } \\
\text { Legal issues and it is frequently expected of UK } \\
\text { nurses to act according to verbal orders, which } \\
\text { differs from Filipino nurses practice of seeing } \\
\text { written doctor's orders. }\end{array}$ \\
\hline
\end{tabular}

This article is protected by copyright. All rights reserved 


\begin{tabular}{|c|c|c|c|c|c|c|}
\hline & & & & & 5) & $\begin{array}{l}\text { The experience of being "new" and feeling } \\
\text { uneasy due to lack of acceptance and warmth } \\
\text { from other staff especially on first work day and } \\
\text { the feeling of constantly being watched and } \\
\text { observed by other staff. }\end{array}$ \\
\hline 2 & $\begin{array}{l}\text { Withers \& Snowball (2003), } \\
\text { United Kingdom (UK) }\end{array}$ & $\begin{array}{l}\text { Explores the expectations and } \\
\text { experiences of Filipino nurses } \\
\text { and examine if their } \\
\text { expectations match their } \\
\text { experience. }\end{array}$ & $\begin{array}{l}\text { Mixed Method using } \\
\text { questionnaire and semi- } \\
\text { structured interview }\end{array}$ & $\begin{array}{l}45 \text { Registered nurses (RNs) for } \\
\text { Quantitative Survey } \\
8 \text { Registered nurses (RNs) for the Semi- } \\
\text { structure interview }\end{array}$ & 2) & $\begin{array}{l}\text { Filipino nurses identify the differences of nursing } \\
\text { role in the Philippines being "very subservient to } \\
\text { doctors and other senior nurses" which is } \\
\text { different in the UK. } \\
\text { Nurses expressed disappointment with low } \\
\text { technology status of century old hospitals which } \\
\text { is opposite to their expectation of modern } \\
\text { facilities as it is the UK. } \\
\text { Staff expressed concern about shift patterns, } \\
\text { staff shortages and heavy workloads and } \\
\text { expected to function as care assistant due to not } \\
\text { paying any credit to previous clinical experience } \\
\text { as a Philippine RN. } \\
\text { Conflict with UK nurses' practice and concept of } \\
\text { handing over unfinished nursing tasks to the } \\
\text { next shift. Filipino nurses tend to finish them first } \\
\text { and also skip their break times to accommodate } \\
\text { these tasks. } \\
\text { Negative discrimination noted by nurses } \\
\text { particularly with the use of own language when } \\
\text { talking to fellow Filipinos. } \\
\text { Adaptation programme has positive impact for } \\
\text { nurses when interviewed and from the surveys. } \\
\text { Nurses are confused with British idioms and } \\
\text { medical abbreviations and use of colloquial } \\
\text { /slang language. }\end{array}$ \\
\hline 3 & $\begin{array}{l}\text { McGonagle, Halloran, \& } \\
\text { O'Reilly (2004), UK }\end{array}$ & $\begin{array}{l}\text { Explore expectations and } \\
\text { experiences of Filipino nurses }\end{array}$ & $\begin{array}{l}\text { Qualitative Approach: } \\
\text { Phenomenology using focus }\end{array}$ & $\begin{array}{l}10 \text { nurses working in Ireland for at least } \\
\text { first } 3 \text { months }\end{array}$ & 1) & $\begin{array}{l}\text { Filipino RNs view nurses in Ireland are less } \\
\text { autonomous than in the Philippines. The }\end{array}$ \\
\hline
\end{tabular}

This article is protected by copyright. All rights reserved 


\begin{tabular}{|c|c|c|c|c|c|c|}
\hline & 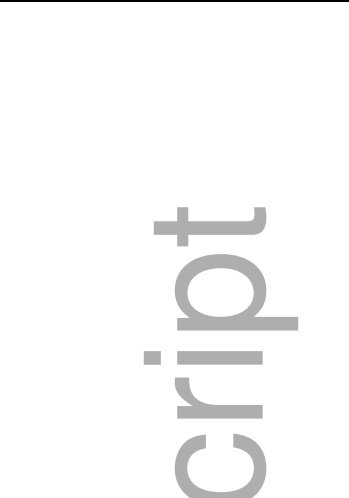 & working in Ireland & $\begin{array}{l}\text { group discussion and } 7 \text { individual } \\
\text { interviews. }\end{array}$ & & 2) & $\begin{array}{l}\text { definition of 'autonomous' is based on providing } \\
\text { meeting physical health care needs. } \\
\text { Minor difficulties with the use of language, } \\
\text { documentation and terms used in Ireland. } \\
\text { Nurses observed that there is a difference in } \\
\text { terms of family's role in looking after older } \\
\text { family members and having them admitted to } \\
\text { residential care is an uncaring act. } \\
\text { Mentorship was a mean of facilitating } \\
\text { orientation. }\end{array}$ \\
\hline 4 & $\begin{array}{l}\text { Hayne, Gerhardt, \& Davis } \\
\text { (2009), US }\end{array}$ & $\begin{array}{l}\text { Examines strategies to } \\
\text { facilitate the cultural } \\
\text { adaptation, job satisfaction } \\
\text { and perception of role and } \\
\text { social support of Filipino } \\
\text { nurses. }\end{array}$ & $\begin{array}{l}\text { Mixed: Quantitative approach } \\
\text { through instruments Nursing } \\
\text { Work Index-Revised (NWI-R) and } \\
\text { Occupational Stress Inventory- } \\
\text { Revised (OSI-R), with Qualitative } \\
\text { Interviews involved (key people } \\
\text { like example Chief Nurse officer) }\end{array}$ & $\begin{array}{l}15 \text { nurses (1male and } 14 \text { females) } \\
\text { Age range is between } 30-51 \text { years. Had } \\
\text { an average of } 14 \text { years' experience in } \\
\text { nursing. }\end{array}$ & 1) & $\begin{array}{l}\text { Filipino nurses felt that workload was fair and } \\
\text { they receive enough training and support. } \\
\text { Roles are perceived to be clear though a quarter } \\
\text { of the respondents perceived that expectations } \\
\text { from the role were not that overt. } \\
\text { Two thirds of the respondents felt that they are } \\
\text { recognised and needs for success were met and } \\
\text { there is a good fit between skills and the } \\
\text { requirement of the job. }\end{array}$ \\
\hline 5 & $\begin{array}{l}\text { Vestal \& Kautz (2009), United } \\
\text { States America (USA) }\end{array}$ & $\begin{array}{l}\text { To assess effectiveness of } \\
\text { support provided to newly } \\
\text { recruited Filipino nurses and to } \\
\text { examine the major challenges } \\
\text { they encounter working in a } \\
\text { USA hospital }\end{array}$ & $\begin{array}{l}\text { Qualitative approach using Focus } \\
\text { Groups. }\end{array}$ & $\begin{array}{l}3 \text { focus groups ( } 22 \text { nurses) } 18 \text { women } \\
\text { and } 4 \text { men in an } 800 \text {-bed US hospital } \\
\text { (magnet-status) }\end{array}$ & 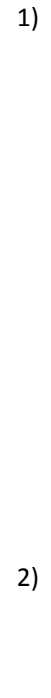 & $\begin{array}{l}\text { Differences in nursing practice } \\
\text { a. Pertaining to technology (automatic } \\
\text { equipment) } \\
\text { b. Providing personal care to patients which, } \\
\text { in the Philippines is normally provided by } \\
\text { family members of the patient (despite } \\
\text { increased patient to nurse ratio) } \\
\text { c. Entry level of practice in the USA is } \\
\text { different from the Philippines and patient } \\
\text { values are different in the US in terms of } \\
\text { respect. } \\
\text { Nurses are generally satisfied with their jobs } \\
\text { (few expressed concern with same pay scale } \\
\text { even after achieving a master's education), }\end{array}$ \\
\hline
\end{tabular}

This article is protected by copyright. All rights reserved 


\begin{tabular}{|c|c|c|c|c|c|c|}
\hline & & & & & & $\begin{array}{l}\text { however encountered issues such as } \\
\text { stereotyping from staff and patients, which } \\
\text { requires Filipino nurses to prove oneself over } \\
\text { and over again. }\end{array}$ \\
\hline 6 & Ronquillo (2012), Canada & $\begin{array}{l}\text { Examine the transition } \\
\text { experience of Filipino nurses } \\
\text { who immigrated in Canada }\end{array}$ & $\begin{array}{l}\text { Qualitative: Oral history through } \\
\text { individual interviews (in person } \\
\text { or by phone) using semi- } \\
\text { structured interview guide }\end{array}$ & $\begin{array}{l}9 \text { nurses (females) in } 2 \text { Canadian } \\
\text { provinces }\end{array}$ & 1) & $\begin{array}{l}\text { Differences in expectations and experiences of } \\
\text { autonomy being an RN in Canada. New } \\
\text { expectations identified being a nurse who have } \\
\text { decision-making responsibilities and differences } \\
\text { with their working relationship to physicians. } \\
\text { Less hierarchal relationship and nursing } \\
\text { autonomy is evident. One participant who } \\
\text { worked from a developed country shared a } \\
\text { different impression that Canadian practice of } \\
\text { nursing has lesser autonomy than the UK. } \\
\text { Perceived discrimination and the feeling of being } \\
\text { "foreign or outsider" while keeping to prove } \\
\text { oneself for acceptance among colleagues and } \\
\text { patients were viewed as transition issues } \\
\text { encountered by Filipino nurses in Canada. }\end{array}$ \\
\hline 7 & $\begin{array}{l}\text { Connor \& Miller (2014), } \\
\text { United States of America } \\
\text { (USA) }\end{array}$ & $\begin{array}{l}\text { Explore the stresses and work } \\
\text { experience of Filipino } \\
\text { immigrant nurses. }\end{array}$ & $\begin{array}{l}\text { Cross-sectional qualitative } \\
\text { research } \\
\text { In-depth interviews (semi- } \\
\text { structured interview guide) }\end{array}$ & $\begin{array}{l}20 \text { Filipino RNs (all females) between } \\
28-48 \text { years old and have lived in the US } \\
\text { from 2- } 17 \text { years. }\end{array}$ & 1) & $\begin{array}{l}\text { Immigration stressors is linked with work-relatec } \\
\text { stress such as: } \\
\text { a. Language and communication issues } \\
\text { b. Non-acceptance and Discrimination in the } \\
\text { workplace } \\
\text { Cultural differences (interdependence, reluctant } \\
\text { to speak up and attitude towards work) }\end{array}$ \\
\hline
\end{tabular}

This article is protected by copyright. All rights reserved 
Table 1

Selection Criteria

\begin{tabular}{|c|c|c|}
\hline & & \multirow[b]{2}{*}{ Exclusion criteria } \\
\hline \multicolumn{2}{|c|}{ Inclusion criteria } & \\
\hline & $\begin{array}{l}\text { Primary research articles published } \\
\text { on academic, peer-reviewed } \\
\text { journals from } 2000 \\
\text { - Full text articles published in English } \\
\text { and has retrievable English } \\
\text { equivalent } \\
\text { - Research focussing solely Filipino } \\
\text { nurses. }\end{array}$ & $\begin{array}{l}\text { - } \\
\text { - } \text { Rublished before year } 2000 \\
\text { nurses involving other migrant } \\
\text { - } \quad \text { Research articles with no English } \\
\text { publication version }\end{array}$ \\
\hline
\end{tabular}

Table 3. Themes and Subthemes*

This article is protected by copyright. All rights reserved 


\begin{tabular}{l|l}
\hline \multicolumn{1}{c}{ Differences in the Practice of Nursing } & Challenges in the Practice of Nursing \\
$\begin{array}{l}\text { a. Work Process* } \\
\text { b. Differing Roles* }\end{array}$ & b. Work-related difficulties* \\
c. Differing Autonomy* &
\end{tabular}

This article is protected by copyright. All rights reserved 
Figure 1. PRISMA FLOWCHART for Literature Selection Process

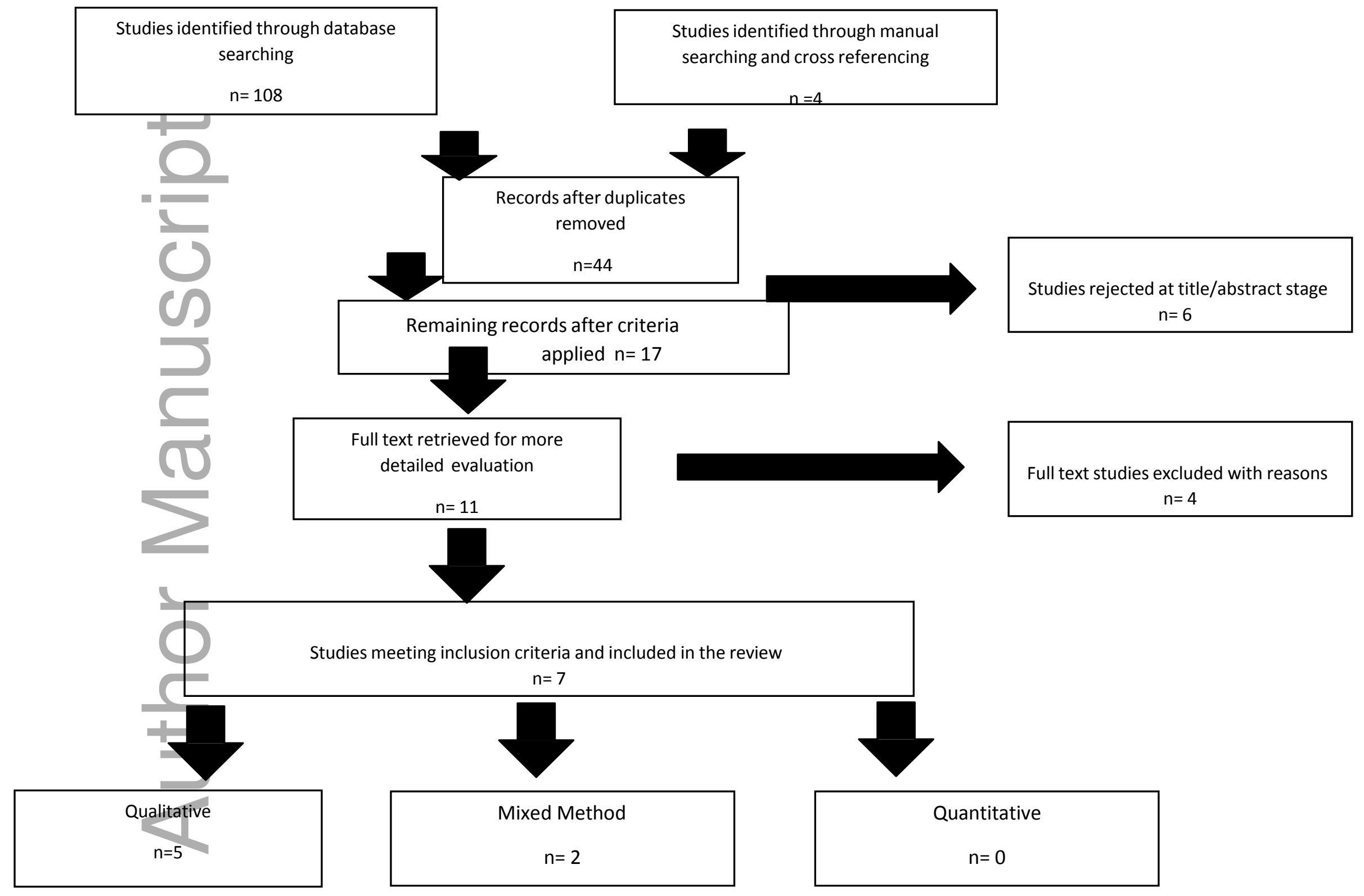

(Moher et al. 2009)

This article is protected by copyright. All rights reserved 


\section{University Library}

\section{- M M I N E R VA A gateway to Melbourne's research publications}

Minerva Access is the Institutional Repository of The University of Melbourne

Author/s:

Montayre, J;Montayre, J;Holroyd, E

Title:

The global Filipino nurse: An integrative review of Filipino nurses' work experiences

Date:

2018-05-01

Citation:

Montayre, J., Montayre, J. \& Holroyd, E. (2018). The global Filipino nurse: An integrative

review of Filipino nurses' work experiences. JOURNAL OF NURSING MANAGEMENT, 26 (4), pp.338-347. https://doi.org/10.1111/jonm. 12552.

Persistent Link:

http://hdl.handle.net/11343/293581 